\title{
Neuropsychiatric symptoms in Mild Cognitive Impairment
}

\author{
Demet IIlhan Algin ${ }^{1 *}$, Alev Kilicoglu², Demet Ozbabalık ${ }^{3}$ \\ From $1^{\text {st }}$ International Congress on Neurobiology and Clinical Psychopharmacology \\ and European Psychiatric Association Conference on Treatment Guidance \\ Thessaloniki, Greece. 19-22 November 2009
}

\section{Background}

Mild cognitive impairment (MCI) is an etiologically heterogeneous condition that is characterized by cognitive changes without impairment of activities of daily living and insufficient to represent dementia. $\mathrm{MCI}$ is an important risk state for Alzheimer dementia [1,2].

\section{Materials and methods}

A total of 30 subjects, aged more than 60 years old, with either MCI $(\mathrm{n}=16)$ or control group $(\mathrm{n}=14)$ were studied. Neuropsychiatric symptoms (NPS) were assessed using the Neuropsychiatric Inventory scale(NPI). Individual subscores of the 10 NPI symptoms and total NPI scores were compared between the MCI patients and control patients. We identified the prevalence of the symptoms in each group and differences between two groups.

\section{Results}

The most common symptoms in the MCI group were dysphoria (39\%), apathy (39\%), irritability (29\%), anxiety (25\%) and depression (\%23). There were significant differences in apathy, dysphoria, irritability, anxiety, agitation, and aberrant motor behavior between the MCI and control groups. There was a significant difference between the MCI and control groups on total NPI scores $(\mathrm{p}<0.05)$.

\section{Conclusions}

The significant differences between MCI and control groups according to NPI scores are important for drawing attention to both differentiating MSI and psychiatric symptoms and their comorbidity. For this reason it is

'Department of Neurology, Dumlupinar University, Kutahya, Turkey important to diagnose MCI with detailed examination without ignoring psychiatric symptoms.

\section{Author details}

'Department of Neurology, Dumlupinar University, Kutahya, Turkey. 2Department of Psychiatry, Dumlupinar University, Kutahya, Turkey.

${ }^{3}$ Department of Neurology, Eskisehir Osmangazi University, Eskisehir, Turkey.

Published: 22 April 2010

\section{References}

1. Apostolova $L G$, Cummings $J$ : Neuropsychiaric manifestations in mild cognitive impairment: a systematic review of the literature. Dement Geriatr Cogn Disord 2008, 25(2):115-26.

2. Hwang TJ, Masterman DL, Ortiz F, Fairbanks LA, Cummings JL: Mild cognitive impairment is associaed with characteristic neuropsychiatric symptoms. Alzheimer Dis Assoc Disord 2004, 18(1):17-21.

doi:10.1186/1744-859X-9-S1-S166

Cite this article as: Algin et al:: Neuropsychiatric symptoms in Mild Cognitive Impairment. Annals of General Psychiatry 2010 9(Suppl 1):S166

Submit your next manuscript to BioMed Central and take full advantage of:

- Convenient online submission

- Thorough peer review

- No space constraints or color figure charges

- Immediate publication on acceptance

- Inclusion in PubMed, CAS, Scopus and Google Scholar

- Research which is freely available for redistribution 